\title{
Burden of Systemic Lupus Erythematosus on Work Productivity and Daily Living Activity: A Cross-Sectional Study Among Malaysian Multi-Ethnic Cohort
}

\author{
Fakhriah ABU BAKAR'10, Syahrul SAZLIYANA SHAHARIR ${ }^{1} \mathbb{B}$, Rozita MOHD $^{2} \mathbb{D}$, \\ Mohd Shahrir MOHAMED SAID ${ }^{1}$, Sakthiswary RAJALINGHAM ${ }^{1}\left({ }^{10}\right.$, Kong WEI YEN ${ }^{2}$ (i) \\ ${ }^{1}$ Department of Internal Medicine, Rheumatology Unit, Universiti Kebangsaan Malaysia Medical Centre, Kuala Lumpur, Malaysia \\ ${ }^{2}$ Department of Internal Medicine, Nephrology Unit, Universiti Kebangsaan Malaysia Medical Centre, Kuala Lumpur, Malaysia
}

\begin{abstract}
Objectives: This study aims to assess the self-reported work productivity and activity daily living (ADL) impairment among Malaysian patients with systemic lupus erythematosus (SLE) and to examine their associated factors.

Patients and methods: This cross-sectional study included 167 SLE patients (21 males, 146 females; mean age $38.2 \pm 9.8$ years; range, 20 to 60 years) recruited from the outpatient Rheumatology and Nephrology clinics. Face-to-face interviews were conducted to record patients' socio-demographics (age, sex, ethnicity, marital status, and occupation) and SLE disease characteristics (system involvement, age onset, and presence of organ damage). Disease activity was assessed using the Systemic Lupus Erythematosus Disease Activity Index-2000 (SLEDAI-2K). Short form 36 (SF-36) was used to determine health-related quality of life (HRQoL) while Work Productivity and Activity Impairment (WPAI) questionnaire was used to assess the four domains of absenteeism, presenteeism, overall work productivity, and non-work related ADL impairment. Univariate analyses and multivariable regression analysis examined the association of demographic variables, SLE disease characteristics, and activity with reduced $\mathrm{HRQ}$ oL and WPAI scores.

Results: The majority of the patients were Malays (59.3\%), followed by Chinese (34.7\%) and Indian (3.6\%) patients. More than two-thirds of the patients reported some degree of impairment in their work productivity and ADL due to the disease. The absenteeism rate was $10.4 \%$ in the past one week and their indirect costs were 2,875.17 Malaysian ringgits (US \$701.22) in the past seven days. Significant predictors of higher work productivity and ADL impairment scores were higher disease activity, more frequent SLE flares, lupus nephritis, and hematological involvement of SLE. Patients with higher work productivity and ADL impairment scores were also strongly associated with poor QoL. No ethnic disparities of work productivity and ADL impairment were found.

Conclusion: Systemic lupus erythematosus significantly affected the overall productivity in work and non-work related activity in our Malaysian multi-ethnic cohort and both impairments were significantly associated with poor QoL.

Keywords: Lupus, nephritis, productivity, work.
\end{abstract}

Systemic lupus erythematosus (SLE) is a chronic autoimmune disease which predominantly affects young individuals of prime working years. ${ }^{1}$ There is no cure for this disease and its course is variable and unpredictable. ${ }^{2}$ Disability and organ damage may ensue if the disease is not adequately controlled. Generally, the prevalence of SLE around the world is estimated between 30 to 300 individuals for every 100,000 people of the country. Malaysia is a multi-ethnic country and the reported prevalence of SLE was 43/100,000. In Kuala Lumpur, the capital city of Malaysia, the Chinese have the highest prevalence of SLE $(57 / 100,000)$, followed by Malays $(33 / 100,000)$ and Indians $(14 / 100,000) .^{3}$

Received: January 15, 2019 Accepted: June 28, 2019 Published online: February 07, 2020

Correspondence: Syahrul Sazliyana Shaharir, MD. Department of Internal Medicine, Rheumatology Unit, Universiti Kebangsaan Malaysia Medical Centre, 56000 Kuala Lumpur, Malaysia. Tel: 60123730137 e-mail: sazliyana@hotmail.com 
Apart from disease activity, the assessment of the quality of life (QoL) has been included as one of the important patient-reported outcome instruments and this has been strongly advocated by the Food and Drug Administration and the European Medicines Agency. ${ }^{4,5}$ This is to enable a holistic approach in the management of SLE. Indeed, the disease has a profound deleterious impact towards QoL which does not correlate with disease activity and damage. ${ }^{6}$ Extensive reports in the literature conclude that poor QoL in SLE is a result from a complex interaction between disease severity, psychosocial factors, and poor socio-economic characteristics. ${ }^{7}$

Another important detrimental consequence of SLE is functional and work productivity impairment as up to 50\% of SLE patients were found to be incapable for employment. ${ }^{8,9}$ Work productivity of those who are employed is also significantly impaired with reduced working hours ${ }^{10}$ and high rate of absenteeism. ${ }^{11}$ In the United States (US), it has been reported that absenteeism accounts for 2.3 sick days $/$ month $^{12}$ among employed SLE patients compared to a 0.3 sick days/month in the general US population in $2016 .{ }^{13}$ This has taken a significant economic toll due to the increase in the indirect costs of the disease. ${ }^{12,14}$ Despite the substantial negative impact of SLE towards work productivity, it is not part of a routine assessment in SLE patients.

A great number of studies on work and healthrelated QoL (HRQoL) impairment have targeted predominantly Caucasian populations ${ }^{6,11,15-19}$ and very scarce data are available from Asian patients including Malays despite more severe disease with high renal involvement. ${ }^{20}$ Thus, examining the magnitude of the disease burden and risk factors is needed to increase our understanding of the disease and provide further evidence as well as to increase the awareness of employers, social welfare and policy-makers to collaborate with health-care institutions in improving the overall management of SLE by addressing worksite modification and compensatory strategies. Therefore, in this study, we aimed to assess the self-reported work productivity and activity daily living (ADL) impairment among Malaysian patients with SLE and to examine their associated factors.

\section{PATIENTS AND METHODS}

This cross-sectional study included 167 consecutive SLE patients (21 males, 146 females; mean age $38.2 \pm 9.8$ years; range, 20 to 60 years) attending the outpatient Nephrology and Rheumatology clinics of Universiti Kebangsaan Malaysia Medical Centre (UKMMC) between March 2017 and July 2017. All patients fulfilled the 1997 revised American College of Rheumatology (ACR) ${ }^{21}$ or Systemic Lupus International Collaborating Clinics (SLICC) 2012 classifications criteria of SLE. ${ }^{22}$ All included patients were employed at the time of the study to be assessed on work productivity. The study protocol was approved by the Universiti Kebangsaan Malaysia Research Ethics Committee. A written informed consent was obtained from each patient. The study was conducted in accordance with the principles of the Declaration of Helsinki.

Information on demographic characteristics including age, sex, ethnicity, marital status, income and educational levels was obtained from medical records and clinical interviews. Meanwhile, information on disease characteristics (age at diagnosis, duration of disease, organ or system involvement) was obtained from medical records and electronic prescriptions.

Patients' socio-economic characteristics were recorded as education level (primary, secondary, tertiary or above) and marital status (single/widow/ separate/divorced or married). In this study, lower education level was defined as patients who received formal education up to secondary education, which is equivalent to the duration of a formal education of $\leq 11$ years. ${ }^{23}$ Patients were also asked to state their employment and their type of work was further categorized as non-professionals and professionals. Professional occupation was defined according to the Malaysian Standard Classification of Occupation 2008, which included manager and sub-sectors professionals. Meanwhile, non-professionals referred to clerical support workers, sales and services workers, and technical or skilled labor workers. ${ }^{24}$ Their monthly incomes were also recorded.

Disease activity was measured using the Systemic Lupus Erythematosus Disease Activity Index-2000 (SLEDAI-2K). ${ }^{25}$ This is a validated 
disease activity index with higher scores indicating greater degree of disease activity. The cumulative of SLE flare frequency was determined from the medical records and it was defined as any new increase in disease activity in one or more organ systems involving new or worse clinical signs and symptoms and/or laboratory measurements which required an increase in the steroid dose or addition of non-steroidal antiinflammatory drugs, hydroxychloroquine or other immunosuppressive therapy. ${ }^{26}$

The organ damage severity was measured using the SLICC/ACR Damage Index. This was designed and validated to capture non-reversible organ damage which was not related to the active disease, lasting for at least six months.

Patients' HRQoL was assessed using the Medical Outcomes Study Short Form 36 (SF-36) questionnaire. ${ }^{27}$ This questionnaire was validated and is reliable to be used in SLE patients ${ }^{28}$ and among the Malaysian population. ${ }^{29}$ It is a selfadministered questionnaire consisting of eight scaled scores that cover the whole aspect of well-being: physical functioning, role limitation due to physical problems, bodily pain, general health perception, vitality, social functioning, role limitation due to emotional problems, and mental health. Each scale is directly transformed into a 0-100 scale on the assumption that each question carries equal weight. The total average HRQoL scores from the eight domains were also calculated with lower scores indicating more severe disability.

Face-to-face interviews were conducted to assess patients' work productivity. Work
Productivity and Activity Impairment (WPAI) questionnaire was used, which was validated ${ }^{30}$ and used in several diseases including SLE. ${ }^{18}$ The WPAI questionnaire contains six question items that measure work impairment due to SLE during the prior seven days of study visit (Table 1). The six items are then formulated into four primary outcomes which include (i) absenteeism (defined as the number of hours a patient missed from work due to their health over the past seven days, (ii) presenteeism (defined as percentage impairment of productivity during working; Q5/10), (iii) overall work productivity impairment (combination of absenteeism and presenteeism domains; $\mathrm{Q} 2 /(\mathrm{Q} 2+\mathrm{Q} 4)+([1-\mathrm{Q} 2 /(\mathrm{Q} 2+\mathrm{Q} 4]) \times(\mathrm{Q} 5 / 10)$ and (iv) daily activity impairment (defined as percentage of impairment in activity outside of work; Q6/10). WPAI of each domain was expressed as percentage (0 to 100), with higher percentage corresponding to greater impairment. Total WPAI scores were also calculated by adding all the scores from the four domains. Indirect costs of absenteeism over the past seven days were estimated using the "lost wages method". ${ }^{31}$ Therefore, the total indirect costs were calculated by multiplying the average hourly salary of the patients with the total hours of missing from workplace for the past seven days.

\section{Statistical analysis}

Data were analyzed using the IBM SPSS version 23.0 software (IBM Corp., Armonk, NY, USA). Variables and data were reported using descriptive statistics. Spearman's correlation analyses were performed to determine the correlation between continuous variables with the percentage of the four different productivity impairment WPAI

Table 1. Work productivity and activity impairment questionnaire

\begin{tabular}{cl}
\hline Question & Items \\
\hline 1 & Current employment (Yes or No) \\
2 & Hours work missed due to health problems related to SLE \\
3 & Hours work missed for other reasons (eg: vacation, holidays, appointments) \\
4 & Total hours actually worked \\
5 & The degree that SLE affects productivity while working (0-10 points scale, where 0 is the lowest degree) \\
6 & The degree that SLE impacts regular activities (0-10 points scale, where 0 is the lowest degree). \\
\hline SLE: Systemic lupus erythematosus.
\end{tabular}


domains. Meanwhile, for categorical variables, Student's t-test or Mann-Whitney U test was used to determine their associations with the WPAI scores. A $p$ value $<0.05$ was considered statistically significant. In this study, a multivariable linear regression analysis was performed to determine the independent factors of lower work productivity ad ADL impairment.

\section{RESULTS}

Patients' disease duration was $13.1 \pm 6.7$ years. Majority had tertiary education $(74.8 \%, \mathrm{n}=125)$ and half of them were in non-professional type of employment ( $n=90,53.9 \%)$. More than two-thirds of the patients had musculoskeletal manifestation of SLE $(n=143,85.6 \%)$ while $71.9 \%$ of them had renal involvement. Up to $50 \%$ of them had mucocutaneous and hematological manifestations.

All domains of the HRQoL were impaired, with the most affected being role limitation on physical health (mean score 65.2 \pm 38.8 ) and the least affected being pain (mean score 81.2 \pm 17.6 ). Table 2 illustrates the baseline socio-demographic, disease characteristics and the mean scores of the SF-36 domains among the SLE patients.

Table 2. Baseline socio-demographic, disease characteristics and HRQoL domains of SLE patients

\begin{tabular}{|c|c|c|c|}
\hline Variables & $\mathrm{n}$ & $\%$ & Mean \pm SD \\
\hline Age (year) & & & $38.2 \pm 9.8$ \\
\hline Disease duration (year) & & & $13.1 \pm 6.7$ \\
\hline \multicolumn{4}{|l|}{ Sex } \\
\hline Male & 21 & 12.6 & \\
\hline Female & 146 & 87.4 & \\
\hline \multicolumn{4}{|l|}{ Ethnicity } \\
\hline Malay & 99 & 59.3 & \\
\hline Chinese & 58 & 34.7 & \\
\hline Indian & 6 & 3.6 & \\
\hline Others & 4 & 2.4 & \\
\hline \multicolumn{4}{|l|}{ Marital status } \\
\hline Married & 110 & 65.9 & \\
\hline Single/divorcee/widow & 57 & 34.1 & \\
\hline \multicolumn{4}{|l|}{ Education level } \\
\hline Primary & 6 & 3.6 & \\
\hline Secondary & 36 & 21.6 & \\
\hline Tertiary and above & 125 & 74.8 & \\
\hline \multicolumn{4}{|l|}{ Employment } \\
\hline Professional & 77 & 46.1 & \\
\hline Non-professional & 90 & 53.9 & \\
\hline \multicolumn{4}{|c|}{ Systemic lupus erythematosus system involvement } \\
\hline Musculoskeletal & 143 & 85.6 & \\
\hline Renal & 120 & 71.9 & \\
\hline Mucocutaneous & 88 & 52.7 & \\
\hline Hematology & 87 & 52.1 & \\
\hline Neuropsychiatric & 11 & 12.6 & \\
\hline \multicolumn{4}{|l|}{ Short Form 36 domain } \\
\hline Physical functioning & & & $78.9 \pm 20.9$ \\
\hline Role limitation on physical health & & & $65.2 \pm 38.8$ \\
\hline Pain & & & $81.2 \pm 17.6$ \\
\hline General health & & & $74.4 \pm 21.1$ \\
\hline Role limitation on emotional & & & $65.6 \pm 39.2$ \\
\hline Energy & & & $75.2 \pm 80.0$ \\
\hline Emotional well-being & & & $77.3 \pm 17.5$ \\
\hline Social functioning & & & $80.8 \pm 16.8$ \\
\hline
\end{tabular}


A total of 17 patients (10.4\%) reported missed work (absenteeism) due to health problems in the past one week and their median hours of missing work was four (interquartile range 5) hours/week. The total indirect cost of absenteeism for the past seven days was 2,875.17 Malaysian ringgits (US\$701.22). No significant associations were found between the various socio-demographics, disease characteristics and activity with absenteeism reported for the week prior to the study.

Table 3. Spearman's correlations of factors associated with overall work productivity and daily activity impairment scores

\begin{tabular}{|c|c|c|c|c|c|c|}
\hline & \multicolumn{3}{|c|}{ WPAI productivity scores } & \multicolumn{3}{|c|}{ WPAI daily activity } \\
\hline & Mean \pm SD & $r_{s}$ & $p$ & Mean \pm SD & $\mathrm{r}_{\mathrm{s}}$ & $p$ \\
\hline Age (year) & & -0.04 & 0.57 & & -0.001 & 0.99 \\
\hline Age onset (year) & & -0.03 & 0.74 & & -0.03 & 0.67 \\
\hline Disease duration (year) & & -0.06 & 0.45 & & 0.02 & 0.37 \\
\hline SLEDAI-2K score & & 0.22 & $0.006^{*}$ & & 0.20 & $0.01^{*}$ \\
\hline SLE flare frequency & & 0.22 & $0.006^{*}$ & & 0.26 & $0.001^{*}$ \\
\hline SLICC ACR damage index & & 0.03 & 0.69 & & 0.06 & 0.49 \\
\hline $\begin{array}{l}\text { Sex } \\
\quad \text { Male } \\
\text { Female }\end{array}$ & $\begin{array}{l}21.3 \pm 17.5 \\
20.3 \pm 19.5\end{array}$ & & 0.84 & $\begin{array}{l}17.6 \pm 16.6 \\
20.8 \pm 17.5\end{array}$ & & 0.43 \\
\hline $\begin{array}{l}\text { Ethnicity } \\
\text { Malay } \\
\text { Chinese } \\
\text { Indian } \\
\text { Others }\end{array}$ & $\begin{array}{l}23.5 \pm 21.5 \\
15.5 \pm 14.5 \\
23.0 \pm 17.9 \\
17.0 \pm 18.7\end{array}$ & & 0.12 & $\begin{array}{l}22.3 \pm 19.4 \\
17.4 \pm 15.5 \\
22.0 \pm 14.8 \\
20.4 \pm 17.8\end{array}$ & & 0.46 \\
\hline $\begin{array}{l}\text { Marital status } \\
\text { Married } \\
\text { Single }\end{array}$ & $\begin{array}{l}22.3 \pm 21.3 \\
16.8 \pm 13.8\end{array}$ & & 0.08 & $\begin{array}{l}21.7 \pm 18.9 \\
18.0 \pm 15.3\end{array}$ & & 0.21 \\
\hline $\begin{array}{l}\text { Education level } \\
\text { Low } \\
\text { High }\end{array}$ & $\begin{array}{l}20.5 \pm 15.8 \\
20.5 \pm 20.3\end{array}$ & & 0.99 & $\begin{array}{l}22.7 \pm 16.2 \\
19.7 \pm 18.4\end{array}$ & & 0.35 \\
\hline $\begin{array}{l}\text { Type of work } \\
\text { Professional } \\
\text { Non-professional }\end{array}$ & $\begin{array}{l}19.6 \pm 18.7 \\
21.2 \pm 19.8\end{array}$ & & 0.61 & $\begin{array}{l}20.3 \pm 19.1 \\
20.6 \pm 16.8\end{array}$ & & 0.92 \\
\hline \multicolumn{7}{|l|}{ SLE manifestation } \\
\hline $\begin{array}{l}\text { Lupus nephritis } \\
\text { Yes } \\
\text { No }\end{array}$ & $\begin{array}{l}22.6 \pm 20.9 \\
15.0 \pm 12.6\end{array}$ & & $0.02^{*}$ & $\begin{array}{l}22.2 \pm 18.9 \\
15.9 \pm 14.1\end{array}$ & & $0.04^{*}$ \\
\hline $\begin{array}{l}\text { Hematological } \\
\text { Yes } \\
\text { No }\end{array}$ & $\begin{array}{l}26.6 \pm 22.5 \\
15.1 \pm 13.2\end{array}$ & & $<0.001^{*}$ & $\begin{array}{l}25.1 \pm 20.4 \\
15.7 \pm 13.1\end{array}$ & & $0.001^{*}$ \\
\hline $\begin{array}{l}\text { Musculoskeletal } \\
\text { Yes } \\
\text { No }\end{array}$ & $\begin{array}{l}20.8 \pm 19.4 \\
18.7 \pm 18.4\end{array}$ & & 0.63 & $\begin{array}{l}19.1 \pm 19.8 \\
20.6 \pm 17.6\end{array}$ & & 0.71 \\
\hline $\begin{array}{l}\text { Mucocutaneous } \\
\text { Yes } \\
\text { No }\end{array}$ & $\begin{array}{c}17.2 \pm 17.1 \\
24.1 \pm 20.7\end{array}$ & & $0.02^{*}$ & $\begin{array}{l}18.4 \pm 15.6 \\
22.7 \pm 19.8\end{array}$ & & 0.12 \\
\hline Average SF-36 scores & & & $\begin{array}{c}0.93 \\
<0.001^{*}\end{array}$ & & & $\begin{array}{c}0.85 \\
<0.001^{*}\end{array}$ \\
\hline
\end{tabular}

WPAI: Work Productivity and Activity Impairment; SD: Standard deviation; SLEDAI-2K: Systemic Lupus Erythematosus Disease Activity Index-2000; SLE: Systemic lupus erythematosus; SLICC ACR: Systemic Lupus International Collaborating Clinics American College of Rheumatology; SF-36: Short Form 36; * Significant $p$ at $<0.05$ 
Table 4. Multiple linear regression analysis of predictors of higher work impairment and non-work related activity daily living impairment scores

\begin{tabular}{|c|c|c|c|c|c|}
\hline WPAI scores & Factors & Regression coefficient $(\beta)$ & $\operatorname{SE}(\beta)$ & $95 \% \mathrm{CI}$ of $\mathrm{OR}$ & $p$ \\
\hline \multirow{6}{*}{ 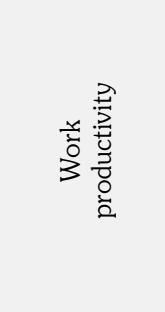 } & SLE flare frequency & 0.82 & 0.08 & -0.76 to 2.38 & 0.31 \\
\hline & Hematology & 4.07 & 0.10 & -1.74 to 9.74 & 0.17 \\
\hline & Mucocutaneous & -4.44 & -0.12 & -9.81 to 0.33 & 0.10 \\
\hline & Lupus nephritis & 3.84 & 0.09 & -2.38 to 10.05 & 0.22 \\
\hline & SLEDAI-2K score & -0.15 & -0.03 & -0.97 to 0.69 & 0.72 \\
\hline & Average SF-36 score & -0.41 & -0.41 & -0.55 to -0.22 & $<0.01^{*}$ \\
\hline \multirow{5}{*}{ 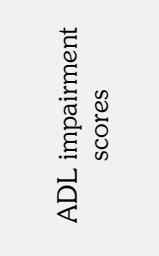 } & SLE flare frequency & 1.43 & 0.14 & 0.06 to 2.79 & $0.04^{*}$ \\
\hline & Average SF-36 scores & -0.42 & -0.45 & -0.54 to -0.29 & $<0.01^{*}$ \\
\hline & Hematology & 3.95 & 0.11 & -1.22 to 9.11 & 0.13 \\
\hline & Lupus nephritis & 1.77 & 0.61 & -3.97 to 7.52 & 0.58 \\
\hline & SLEDAI-2K score & 0.02 & 0.003 & -0.76 to 0.79 & 0.98 \\
\hline
\end{tabular}

A total of $76.6 \%(n=128)$ reported some degree of impairment (score $>0$ ) while working (presenteeism) with their average impairment scores of $17.8 \pm 18.2$. Meanwhile, a total of $80.8 \%$ $(n=135)$ reported work productivity impairment (absenteeism + presenteeism) with their average scores of $20.5 \pm 19$. A total of 142 patients (85.0\%) reported ADL impairment with their mean impairment scores of $20.4 \pm 17.8$.

Higher work productivity and ADL impairment scores were significantly correlated with SLEDAI-2K score, flare frequency, lupus nephritis (LN) and hematological manifestations of SLE. Presence of mucocutaneous involvement in SLE was significantly associated with lower work productivity impairment score (Table 3).

Multiple linear regression analysis, which included all the significant factors above, revealed that lower average HRQoL was significantly associated with higher work productivity and ADL impairment scores. In addition, frequent SLE flare was associated with impairment in ADL (Table 4).

\section{DISCUSSION}

Systemic lupus erythematosus mainly affects young females during the career-building phase of life. Therefore, burden of the disease towards patients' work productivity ${ }^{11,16,18,19,32}$ and QoL ${ }^{6}$ is substantial. Despite the fact that the Asian population displays more severe SLE, ${ }^{33}$ there is still a relative paucity of studies quantifying the socio-economic burden of the disease which may indirectly influence patients' QoL. SLE is known to reduce patient's ability to work and hence results in reduced productivity and working hours. ${ }^{18,34}$ Similarly, our study demonstrated that up to two-thirds of our patients had some degree of impairments in their work productivity and ADL due to SLE.

The cumulative flare frequency was one of the factors associated with reduced work and ADL productivity among our cohort. This is consistent with the nature of the disease which runs through unpredictable courses with episodes of exacerbations. Therefore, prevention of disease flares is important to ensure that work productivity remains optimum as diminished productivity may lead to the risk of permanent disability. ${ }^{35}$ Our study has revealed that greater disease activity was significantly correlated with higher work productivity and non-work related ADL impairment scores. Our findings concurred with a US cohort which consisted of predominantly African-American patients ${ }^{16}$ and a SLE Latin 
cohort from Argentina. ${ }^{32}$ Other studies have failed to demonstrate similar associations; $8,17,32,36$ however, they had variabilities in disease activity indices or instruments used.

We reported significant associations of renal and hematological involvement of work productivity and ADL impairment. Patients with SLE, particularly those with active $\mathrm{LN}$, were demonstrated to be more likely to miss work compared to non-LN patients in a multi-ethnic Canadian study (Lupus Nephritis New Emerging Team (LuNNET) study cohort.). ${ }^{15}$ In contrast, the afore-mentioned multi-ethnic US study (Georgians Organized Against Lupus [GOAL] cohort) also revealed that mucocutaneous and musculoskeletal involvement were found to have a significant detrimental impact on workplace productivity, ${ }^{16}$ which was not observed in our cohort. This can be explained by the fact that the mucocutaneous and musculoskeletal manifestations in our patients were rather mild and not significantly associated with joint damage or deformity. ${ }^{20}$ The GOAL cohort, which comprised of predominantly African-American patients, had more chronic cutaneous lupus erythematosus. ${ }^{37}$

Racial disparities in SLE disease manifestations and outcomes have been demonstrated in the multi-ethnic US study and our local populations. ${ }^{20,38,39}$ Severe disease leads to higher burden as African-American patients were reported to have an increased risk of unemployment compared to Caucasians. ${ }^{40}$ Although our earlier study demonstrated that Indian patients had more severe disease with significantly higher organ damage ${ }^{20}$ there were no significant inter-ethnic differences in work productivity and daily activity impairment. However, a small number of Indian patients in this current study may not be able to capture any significant disability; thus, future larger studies are needed to confirm this.

Our study also showed that both work and non-work related productivity impairments were significantly associated with poor QoL measured with SF-36. This finding concurred with the SLE cohort in Argentina ${ }^{32}$ and rheumatoid arthritis populations. ${ }^{41,42}$ However, due to the crosssectional nature of this study, a causal relationship of poor QoL and work productivity could not be ascertained. The relationship between work and QoL is complex as various studies have demonstrated that under-employment had a negative impact towards both mental and physical health. ${ }^{43,44}$ This is probably because of the fact that employment may influence patients' mental health through rewarding jobs and earnings as well as providing a distraction from symptoms. ${ }^{45}$ Employment is also one of the platforms for social interaction and this may also contribute to better QoL. ${ }^{46}$

The one-week indirect cost of absenteeism in our study was equivalent to US\$700. However, since the WPAI does not capture sufficient data such as worker replacement costs and actual productivity losses, the indirect cost calculated may be under-estimated. We also could not calculate the annual indirect cost of productivity lost due to the inadequate data in our study. The published reports on annual indirect cost of productivity loss among SLE patients varied, from US $\$ 2,239$ to US $\$ 35,540$ (year 2010 values), depending on the different costing methods. ${ }^{47}$

There are several limitations of this study. One was the exclusion of healthy controls, which prevented us from performing direct comparisons. Moreover, the study subjects were recruited from outpatient clinics and this may have caused under-reporting of the overall impairment as inpatients were not included. Apart from that, we did not examine the nature of the works as certain occupations that require higher physical demand are associated with workplace activity limitations. ${ }^{11,36}$ Other possible factors that have potential roles in influencing QoL such as social support $^{48}$ and psychological well-being ${ }^{49,50}$ were also not examined in our study. Furthermore, the information on reduced work productivity was based on patient-reported data, hence there was a potential recall bias.

In conclusion, we have revealed that the burden of SLE towards employment and non-work related daily activity was substantial among our multiethnic cohort prompting further evaluation of the socio-economic impact of the disease in our country.

\section{Declaration of conflicting interests}

The authors declared no conflicts of interest with respect to the authorship and/or publication of this article. 


\section{Funding}

This study received a financial funding from Fundamental Research Grant Scheme (FRGS/1/2015/ SKK02/UKM/03/1) from Ministry of Education Malaysia.

\section{REFERENCES}

1. Meller S, Homey B, Ruzicka T. Socioeconomic factors in lupus erythematosus. Autoimmun Rev 2005;4:242-6.

2. Maddison PJ. Is it SLE? Best Pract Res Clin Rheumatol 2002;16:167-80.

3. Wang F, Wang CL, Tan CT, Manivasagar M. Systemic lupus erythematosus in Malaysia: a study of 539 patients and comparison of prevalence and disease expression in different racial and gender groups. Lupus 1997;6:248-53.

4. Strand V, Gladman D, Isenberg D, Petri M, Smolen J, Tugwell P. Endpoints: consensus recommendations from OMERACT IV. Outcome Measures in Rheumatology. Lupus 2000;9:322-7.

5. Holloway L, Humphrey L, Heron L, Pilling C, Kitchen $\mathrm{H}$, Højbjerre $\mathrm{L}$, et al. Patient-reported outcome measures for systemic lupus erythematosus clinical trials: a review of content validity, face validity and psychometric performance. Health Qual Life Outcomes 2014;12:116.

6. McElhone K, Abbott J, Teh LS. A review of health related quality of life in systemic lupus erythematosus. Lupus 2006;15:633-43.

7. Elera-Fitzcarrald C, Fuentes A, González LA, Burgos PI, Alarcón GS, Ugarte-Gil MF. Factors affecting quality of life in patients with systemic lupus erythematosus: important considerations and potential interventions. Expert Rev Clin Immunol 2018;14:915-31.

8. Campbell R Jr, Cooper GS, Gilkeson GS. The impact of systemic lupus erythematosus on employment. J Rheumatol 2009;36:2470-5.

9. Utset TO, Chohan S, Booth SA, Laughlin JC, Kocherginsky M, Schmitz A. Correlates of formal work disability in an urban university systemic lupus erythematosus practice. J Rheumatol 2008;35:1046-52.

10. Partridge AJ, Karlson EW, Daltroy LH, Lew RA, Wright EA, Fossel AH, et al. Risk factors for early work disability in systemic lupus erythematosus: results from a multicenter study. Arthritis Rheum 1997;40:2199-206.

11. Utset TO, Baskaran A, Segal BM, Trupin L, Ogale S, Herberich $\mathrm{E}$, et al. Work disability, lost productivity and associated risk factors in patients diagnosed with systemic lupus erythematosus. Lupus Sci Med 2015;2:e000058.

12. Hammond E, Murimi IB, Lin DH, Kan H, Tierce $\mathrm{J}$, Wang $\mathrm{X}$, et al. Health care utilization and costs of systemic lupus erythematosus (SLE) in the united states: systematic review. Ann Rheum Dis 2017:76(Suppl 2):859-60.
13. Labor Force Statistics from the Current Population Survey UDoL. Available at: https://www.bls.gov/cps/ cpsaat47.htm [Access: November, 2017].

14. Turchetti G, Yazdany J, Palla I, Yelin E, Mosca M. Systemic lupus erythematosus and the economic perspective: a systematic literature review and points to consider. Clin Exp Rheumatol 2012:30:116-22.

15. Aghdassi E, Zhang W, St-Pierre Y, Clarke AE, Morrison S, Peeva V, et al. Healthcare cost and loss of productivity in a Canadian population of patients with and without lupus nephritis. $J$ Rheumatol 2011;38:658-66.

16. Drenkard C, Bao G, Dennis G, Kan HJ, Jhingran PM, Molta CT, et al. Burden of systemic lupus erythematosus on employment and work productivity: data from a large cohort in the southeastern United States. Arthritis Care Res (Hoboken) 2014;66:878-87.

17. Garris C, Oglesby A, Sulcs E, Lee M. Impact of systemic lupus erythematosus on burden of illness and work productivity in the United States. Lupus 2013;22:1077-86.

18. Gordon C, Isenberg D, Lerstrøm K, Norton Y, Nikaï E, Pushparajah DS, et al. The substantial burden of systemic lupus erythematosus on the productivity and careers of patients: a European patient-driven online survey. Rheumatology (Oxford) 2013;52:2292-301.

19. McCormick N, Marra CA, Sadatsafavi M, Kopec JA, Aviña-Zubieta JA. Excess Productivity Costs of Systemic Lupus Erythematosus, Systemic Sclerosis, and Sjögren's Syndrome: A General Population-Based Study. Arthritis Care Res (Hoboken) 2019;71:142-54.

20. Shaharir SS, Hussein H, Rajalingham S, Mohamed Said MS, Abdul Gafor AH, Mohd R, et al. Damage in the Multiethnic Malaysian Systemic Lupus Erythematosus (SLE) Cohort: Comparison with Other Cohorts Worldwide. PLoS One 2016;11:e0166270.

21. Hochberg MC. Updating the American College of Rheumatology revised criteria for the classification of systemic lupus erythematosus. Arthritis Rheum 1997;40:1725.

22. Petri M, Orbai AM, Alarcón GS, Gordon C, Merrill JT, Fortin PR, et al. Derivation and validation of the Systemic Lupus International Collaborating Clinics classification criteria for systemic lupus erythematosus. Arthritis Rheum 2012;64:2677-86.

23. Cheah YK, Poh BK. The determinants of participation in physical activity in malaysia. Osong Public Health Res Perspect 2014;5:20-7.

24. Malaysia MoHR. Malaysia Standard Classification of Occupations. 3rd ed. Available at: http://www.mohr. gov.my [Access: October, 2017].

25. Gladman DD, Ibañez D, Urowitz MB. Systemic lupus erythematosus disease activity index 2000. J Rheumatol 2002;29:288-91.

26. Ruperto N, Hanrahan LM, Alarcón GS, Belmont HM, Brey RL, Brunetta P, et al. International consensus for a definition of disease flare in lupus. Lupus 2011;20:453-62. 
27. Ware JE Jr, Sherbourne CD. The MOS 36-item shortform health survey (SF-36). I. Conceptual framework and item selection. Med Care 1992;30:473-83.

28. Stoll T, Gordon C, Seifert B, Richardson K, Malik $\mathrm{J}$, Bacon PA, et al. Consistency and validity of patient administered assessment of quality of life by the MOS SF-36; its association with disease activity and damage in patients with systemic lupus erythematosus. J Rheumatol 1997;24:1608-14.

29. Sararaks S, Azman AB, Low LL, Rugayah B, Aziah AM, Hooi LN, et al. Validity and reliability of the SF-36: the Malaysian context. Med J Malaysia 2005;60:163-79.

30. Reilly MC, Zbrozek AS, Dukes EM. The validity and reproducibility of a work productivity and activity impairment instrument. Pharmacoeconomics 1993;4:353-65.

31. Berger ML, Murray JF, Xu J, Pauly M. Alternative valuations of work loss and productivity. J Occup Environ Med 2001;43:18-24.

32. Bertoli A, Lopez Pérez MJ, Alba P, Albiero A, Albiero E, Alessio D, et al. AB1097 The Impact of Systemic Lupus Erythematosus on Work Productivity: Data from Patients from the Province of Cordoba, Argentina. Ann Rheum Dis 2015:74(Suppl 2):1267.

33. Thumboo J, Wee H-L. Systemic lupus erythematosus in Asia: is it more common and more severe? APLAR Journal of Rheumatology 2006:9:320-6.

34. Yelin E, Trupin L, Katz P, Criswell L, Yazdany $\mathrm{J}$, Gillis $\mathrm{J}$, et al. Work dynamics among persons with systemic lupus erythematosus. Arthritis Rheum 2007;57:56-63.

35. Scofield L, Reinlib L, Alarcón GS, Cooper GS. Employment and disability issues in systemic lupus erythematosus: a review. Arthritis Rheum 2008;59:1475-9.

36. Al Dhanhani AM, Gignac MA, Beaton DE, Su J, Fortin PR. Work factors are associated with workplace activity limitations in systemic lupus erythematosus. Rheumatology (Oxford) 2014;53:2044-52.

37. Drenkard C, Parker S, Aspey LD, Gordon C, Helmick CG, Bao G, et al. Racial Disparities in the Incidence of Primary Chronic Cutaneous Lupus Erythematosus in the Southeastern US: The Georgia Lupus Registry. Arthritis Care Res (Hoboken) 2019;71:95-103.

38. Yen EY, Shaheen M, Woo JMP, Mercer N, Li N, McCurdy DK, et al. 46-Year Trends in Systemic Lupus Erythematosus Mortality in the United States, 1968 to 2013: A Nationwide Population-Based Study. Ann Intern Med 2017;167:777-85.
39. Shaharir SS, Ghafor AH, Said MS, Kong NC. A descriptive study of the factors associated with damage in Malaysian patients with lupus nephritis. Lupus 2014;23:436-42.

40. Drenkard C, Rask KJ, Easley KA, Bao G, Lim SS. Primary preventive services in patients with systemic lupus erythematosus: study from a population-based sample in Southeast U.S. Semin Arthritis Rheum 2013;43:209-16.

41. Geuskens GA, Hazes JM, Barendregt PJ, Burdorf A. Predictors of sick leave and reduced productivity at work among persons with early inflammatory joint conditions. Scand J Work Environ Health 2008;34:420-9.

42. van Vilsteren M, Boot CR, Knol DL, van Schaardenburg D, Voskuyl AE, Steenbeek R, et al. Productivity at work and quality of life in patients with rheumatoid arthritis. BMC Musculoskelet Disord 2015;16:107.

43. Merchant JA, Kelly KM, Burmeister LF, Lozier MJ, Amendola A, Lind DP, et al. Employment status matters: a statewide survey of quality-of-life, prevention behaviors, and absenteeism and presenteeism. J Occup Environ Med 2014;56:686-98.

44. Orbon KH, Schermer TR, van der Gulden JW, Chavannes NH, Akkermans RP, Schayck OP, et al. Employment status and quality of life in patients with chronic obstructive pulmonary disease. Int Arch Occup Environ Health 2005;78:467-74.

45. Van Dongen CJ. Quality of life and self-esteem in working and nonworking persons with mental illness. Community Ment Health J 1996;32:535-48.

46. Park HK, Chun SY, Choi Y, Lee SY, Kim SJ, Park EC. Effects of social activity on health-related quality of life according to age and gender: an observational study. Health Qual Life Outcomes 2015;13:140.

47. Meacock R, Dale N, Harrison MJ. The humanistic and economic burden of systemic lupus erythematosus: a systematic review. Pharmacoeconomics 2013;31:49-61.

48. Sutcliffe N, Clarke AE, Gordon C, Farewell V, Isenberg DA. The association of socio-economic status, race, psychosocial factors and outcome in patients with systemic lupus erythematosus. Rheumatology (Oxford) 1999;38:1130-7.

49. Dobkin PL, Da Costa D, Dritsa M, Fortin PR, Senécal JL, Goulet JR, et al. Quality of life in systemic lupus erythematosus patients during more and less active disease states: differential contributors to mental and physical health. Arthritis Care Res 1999;12:401-10.

50. Omdal R, Waterloo K, Koldingsnes W, Husby G, Mellgren SI. Fatigue in patients with systemic lupus erythematosus: the psychosocial aspects. J Rheumatol 2003;30:283-7. 